Immunology Letters. 27 (1991) $157-162$

Elsevier

[NILET 01533

\title{
Serum levels of tumor necrosis factor determine the fatal or non- fatal course of endotoxic shock
}

\author{
Tibor Mózes*, Shlomo Ben-Efraim**, Corné J. A. M. Tak, Jan P. C. Heiligers, Pramod R. \\ Saxena and Iván L. Bonta \\ Departmen of Pharmacologı; Faculty of Medicine and Healı Sciences, Erasmus L'nu'ersuly Roulerdam. Roulerdam. The \\ Velherlands
}

(Receised 2 Norember 1990: aceepted 7 Norember 1990)

\section{Summary}

The role of tumor necrosis factor alpha (TNF $\alpha$ ) in endotoxin-induced shock was investigated in pigs receiving $5 \mu \mathrm{g} \mathrm{kg}^{-1}$ of Escherichia coli endotoxin (LPS) during 60 min of continuous infusion into the superior mesenteric artery. LPS concentration in aortic plasma, as determined by a chromogenic Limulus amoebocyte lysate (LAL) test. reached a

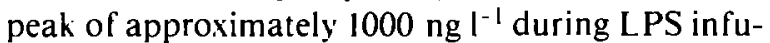
sion, and declined rapidly after discontinuation of the infusion. Serum TNF levels were determined by a bioassay using the $L 929$ murine transformed fibroblast line. Eight of the 17 animals infused with LPS died within $30 \mathrm{~min}$ after beginning LPS administration, while the other 9 pigs survived beyond the experimental observation period of $3 \mathrm{~h}$, although they were in a state of shock. No difference in LPS concentration was found between the surivors and the non-survivors. However, the serum TNF levels in non-survivors were significantly higher than in survivors when measured at $30 \mathrm{~min}$ after beginning LPS administration. In survivors.

Key words: Endorowin: Pig: Shock: TNF

Correspondence to: Tibor Mózes. M.D., Dept. of Pharmacology. Faculty of Medicine and Health Sciences, Erasmus University Rotterdam. P.O. Bos 1738, 3000 DR Rotterdam. The Netherlands.

* On leave from Department of Traumatology, Semmelwets Medical Unuersity. Peterfy Hospital, P.O. Box 76. $14+1$ Budapest, Hungary.

* On leave irom Department of Human Microbiology, Sackler Sihool of Medicine, Tel-Avis Unuersity. Tel-Aıiv. Israel. the peak increase in serum TNF levels was measured at 60 min after the beginning of LPS injection and returned rapidly to the baseline values. Although the role of TNF inducing rapid death seems to be dominant, the hemodynamic, hematology and blood chemistry disturbances seen during shock continued in survivors long after the recurn of TNF to baseline levels. These findings indicate that besides TNF other mediators are also involved in the LPS infusioninduced shock.

\section{Introduction}

The involvement of TNF $\alpha$ as a crucial mediator in shock, inflammation and cachexia has been proposed [1] on the basis of three different lines of evidence. First, increase in TNF levels was reported in animal models of shock and other forms of acute inflammation $[2,3]$. The increase in TNF levels was correlated to the intensity of septic shock and was also found to occur in patients dying from meningococcal septicemia [4]. Second, antibodies against TNF protected septic shock in murine, rabbit and baboon models [5-7]. Third, administration of TNF itself can induce hemodynamic and laboratory changes, which are characteristics for septic shock $[8,9]$.

Some findings indicate, however, that differences exist between shock induced by LPS and shock induced by TNF itself. The kinetics of hemodynamic. hematologic and blood chemistry changes differ between the two kinds of shock [10]. Moreover, the plasma levels of TNF required to induce death are 
much higher than the serum TNF levels induced by a lethal dose of LPS [3]. The treatment with antibody against TNF is not successiul if given $1 \mathrm{~h}$ before administration of bacterial infusion [6]. These data indicate that besides TNF some other inflammatory mediators may play a role in the pathogenesis of endotoxic shock.

During our study on shock induced in pigs by infusion of LPS, we found an almost even distribution in the pig population of susceptibility to the lethal effects of LPS. Thus, this model provided an opportunity to determine the relationship between susceptibility to the lethal effects of LPS infusion and TNF levels, and the hemodynamic, hematologic and blood chemistry changes induced by LPS. The aim of the present work was to investigate the existence of such a relationship.

\section{Materials and Methods}

\subsection{Experimental set-up}

E. coli LPS (5 $\mu \mathrm{g} \mathrm{kg}^{-1}$ of O111 B4, Serva) was infused into the superior mesenteric artery over $60 \mathrm{~min}$ in pigs (female, age 13-15 weeks) anesthetized with pentobarbital sodium $\left(20 \mathrm{mg} \mathrm{kg}^{-1}\right.$, i...) after pre-medication with ketamine $(20 \mathrm{mg} \mathrm{kg}$. i.m.). The animals were subsequently observed for a further period of $120 \mathrm{~min}$. The surgical preparation was performed as described in detail elsewhere [11]. The core temperature was measured with a thermometer (Philips, HP 5311, Japan) attached to the liver. Mean arterial blood pressure (MABP) was continuously monitored by electromanometer using Statham P 23 dB strain gauge (Hato Rey. PR). Cardiac output (CO) was determined intermittently by thermodilution (W'TI Computer, The Netherlands).

\subsection{Experimental protocols}

Group I (sham operated). Three animals were prepared as described above, except that instead of LPS, physiological saline was infused into the superior mesenteric artery. Blood $(5 \mathrm{ml})$ was collected from pulmonary artery for laboratory measurements.

Group II (LPS-induced shock). Seventeen pigs were infused with $5 \mu \mathrm{g} \mathrm{kg}^{-1}$ of $E$. coli LPS into the su- perior mesenteric artery over a 60 -min period and the animals were observed for an additional $120-\mathrm{min}$ period. Blood $(5 \mathrm{ml})$ was collected each time from aorta for LPS and TNF measurements at $10 \mathrm{~min}$ before, 10,30 and $60 \mathrm{~min}$ after the start of LPS infusion. 60 and $120 \mathrm{~min}$ after termination of LPS infusion.

\subsection{Assay for plasma levels of LPS}

Blood for LPS assay was collected in plastic tubes (Falcon 2063, Oxnard, CA. U.S.A.) pre-filled with

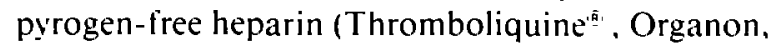
Oss, The Netherlands) at a final concentration of $30 \mathrm{Cl}^{-1}$. After mixing, these tubes were immediately immersed in melting ice. Plasma was obtained by centrifugation at $160 \times \mathrm{g}$ at $4{ }^{\circ} \mathrm{C}$ for $10 \mathrm{~min}$ and plasma aliquots were stored at $-70^{\circ} \mathrm{C}$. LPS was assayed with a chromogenic Limulus test [12]. All assay's were performed in duplicate.

\subsection{Assa. for serum levels of TNF}

Blood was collected in sterile tubes (Costar, Cambridge, MA). Serum uas separated rapidly after coagulation by centrifugation and aliquots were stored at $-20^{\circ} \mathrm{C}$ until assay. TNF activity was determined by measuring the cytostatic effect of TNFa on the murine transformed fibroblast cell line L929 (a gift from W. Fiers, State University of Ghent, Belgium) $[13,14]$. L929 cells were plated in a 96-uell flat-bottomed microtiter plate (NUNC, Roskilde, Denmark) at a density of $1 \times 10^{4}$ cells per well in $25 \mu$ of RPMII- 1640 culture medium. To quadruplicate wells, $25 \mu \mathrm{l}$ medium (control), human recombinant TNF standard solutions $(10,100,1000 \mathrm{U}$ $\mathrm{ml}^{-1}$ ) (Roche Research, Ghent. Belgium) or serum were added (final dilution 1:10). After incubation for $24 \mathrm{~h}$ in humidified atmosphere $\left(\begin{array}{l}7.5 \sigma_{0} \\ \left.\mathrm{CO}_{2}\right)\end{array}\right)$ at $37^{\circ} \mathrm{C}, 50 \mu$ l of a $10-\mu \mathrm{Ci} \mathrm{m}^{-1}\left[{ }^{3} \mathrm{H}\right]$ thymidine (Amersham Laboratories, Amersham, U.K.) solution was added. After $2 \mathrm{~h}$ of incubation L929 cells were harvested on glass fiber filtermats (Shatron Inc., Sterling, VA, U.S.A.). The uptake of $\left[{ }^{3} \mathrm{H}\right]$ thymidine uas measured by liquid scintillation spectroscopy. A standard curve of cytostasis by human recombinant TNF was obtained yielding progressive cytostasis ranging from $10-1000 \mathrm{U} \mathrm{ml}^{-1}$ of TNF. The bioactivity of TNF in experimental samples was deter- 
mined in quadruplicate and compared against the standard curve.

\subsection{Determination of blood chemistry values}

Plasma glucose concentrations were measured by Glucoquant kit (Boehringer, Mannheim, F.R.G.). Laboratory values of blood hemoglobin, hematocrit as well as leukocyte and platelet counts were measured by hematology analyzers (Sysmex CC-108 and Pl-100, Kobe, Japan, as appropriate).

\subsection{Statistical analysis}

All values are expressed as means \pm SEM. The data were evaluated by the two-way analysis of variance (Friedman test) followed by a Wilcoxon-Wilcox test or two-tailed Mann-Whitney U test, as appropriate. A $p$ value of 0.05 or less was considered statistically significant for all tests.

\section{Results}

\subsection{Sham-operated animals}

In sham-operated animals systemic hemodynamic ıariables and laboratory values were stable during the experiment (Table 1, Group I).

\subsection{LPS-treated animals}

Eight of the 17 animals treated with LPS died within 30 min after LPS infusion was started (nonsurvivors), while the other 9 survived the experimental period of $3 \mathrm{~h}$ ( $2 \mathrm{~h}$ after termination of LPS infusion), though in a state of shock (survivors).

Sy'stemic hemodynamics (Table I, Group II). In survivors, mean arterial blood pressure (MABP) gradually decreased and was significantly lower than the baseline from the end of LPS infusion period onwards. In contrast, MABP in the non-survivors dramatically dropped from 15-30 min after the start of LPS infusion. At 25-30 min MABP in this group

TABLE I

Effeets of $E$. coll LPS infusion on hemodynamic and blood parameters in anesthetized pigs.

\begin{tabular}{|c|c|c|c|c|c|c|c|}
\hline & $\begin{array}{l}\text { МАBP } \\
(\mathrm{mmHg})\end{array}$ & $\begin{array}{l}\mathrm{CO} \\
\left(1 \min ^{-1}\right)\end{array}$ & $\begin{array}{l}\text { Temperature } \\
\left({ }^{\circ} \mathrm{C}\right)\end{array}$ & $\begin{array}{l}\mathrm{Hb} \\
(\mathrm{mM} \mid-1)\end{array}$ & $\begin{array}{l}\text { W'BC } \\
(G \mid-1)\end{array}$ & $\begin{array}{l}\text { Platelet } \\
\text { count }\end{array}$ & $\begin{array}{l}\text { Blood } \\
\text { glucose } \\
\left.(\mathrm{mN1})^{-1}\right)\end{array}$ \\
\hline \multicolumn{8}{|c|}{ Group I: sham operated $(n=3)$} \\
\hline Control & $99 \pm 8$ & $2.7 \pm 0.4$ & $38.6 \pm 0.3$ & $5.7 \pm 0.4$ & $13.5 \pm 2.3$ & $350 \pm 49$ & $6.0 \pm 0.24$ \\
\hline $60 \mathrm{~min}$ & $116 \pm 8$ & $2.8 \pm 0.1$ & $39.1 \pm 0.5$ & $6.0 \pm 0.4$ & $20.0 \pm 5.0$ & $340 \pm 48$ & $6.3 \pm 0.26$ \\
\hline $120 \mathrm{~min}$ & $114 \pm 2$ & $2.2 \pm 0.1$ & $39.2 \pm 0.4$ & $6.1 \pm 0.5$ & $20.0 \pm 5.0$ & $330 \pm 49$ & $5.8 \pm 0.17$ \\
\hline $180 \mathrm{~min}$ & $121 \pm 8$ & $2.4 \pm 0.3$ & $39.5 \pm 0.4$ & $6.3 \pm 0.4$ & $20.0 \pm 6.0$ & $330 \pm 52$ & $5.8 \pm 0.36$ \\
\hline \multicolumn{8}{|c|}{ Group II: LPS infusion-induced shock $(n=17)$} \\
\hline \multicolumn{8}{|c|}{ Sursivors $(n=9)$} \\
\hline Control & $108 \pm 3$ & $2.8 \pm 0.3$ & $39.3 \pm 0.3$ & $6.6 \pm 0.2$ & $11.5 \pm 1.5$ & $340 \pm 41$ & $5.3 \pm 0.30$ \\
\hline $15 \mathrm{~min}$ & $106 \pm 5$ & $2.1 \pm 0.3$ & $38.6 \pm 0.2$ & $7.0 \pm 0.2$ & $9.7 \pm 1.2$ & $330 \pm 46$ & $5.5 \pm 0.30$ \\
\hline $30 \mathrm{~min}$ & $89 \pm ?$ & $1.5 \pm 0.1^{*}$ & $38.8 \pm 0.3$ & $7.5 \pm 0.2^{*}$ & $5.4 \pm 1.1^{*}$ & $260 \pm 3^{-*}$ & $5.6 \pm 0.32$ \\
\hline $60 \mathrm{~min}$ & $72 \pm 7 *$ & $2.0 \pm 0.2$ & $39.3 \pm 0.2^{*}$ & $7.5 \pm 0.2^{*}$ & $4.5 \pm 0.8^{*}$ & $230 \pm 33^{*}$ & $5.0 \pm 0.30$ \\
\hline $120 \mathrm{~min}$ & $66 \pm 6^{*}$ & $1.3 \pm 0.1^{\pi}$ & $39.9 \pm 0.3^{*}$ & $7.5 \pm 0.2 *$ & $4.1 \pm 1.2^{*}$ & $230 \pm 38$ & $4.2 \pm 0.20^{*}$ \\
\hline $180 \mathrm{~min}$ & $55 \pm 5 *$ & $1.0 \pm 0.1^{*}$ & $40.5 \pm 0.3^{*}$ & $7.7 \pm 0.3^{*}$ & $5.4 \pm 1.1^{*}$ & $210 \pm 32 *$ & $2.8 \pm 0.40^{*}$ \\
\hline \multicolumn{8}{|c|}{ Non-survivors $(n=8)$} \\
\hline Control & $110 \pm 5$ & $2.8 \pm 0.1$ & $39.3 \pm 0.3$ & $6.1 \pm 0.3$ & $11.4 \pm 0.6$ & $370 \pm 34$ & $5.4 \pm 0.15$ \\
\hline $15 \mathrm{~min}$ & $92 \pm 8$ & $1.9 \pm 0.1$ & $39.5 \pm 0.4$ & $6.5 \pm 0.3$ & $10.2 \pm 0.8$ & $320 \pm 30$ & $6.0 \pm 0.33$ \\
\hline $30 \mathrm{~min}$ & $28 \pm 2^{*}$ & $1.0 \pm 0.1^{*}$ & $39.9 \pm 0.3 *$ & $6.7 \pm 0.2^{7}$ & $6.1 \pm 0.7^{*}$ & $260 \pm 31^{*}$ & $9.4 \pm 0.84^{*}$ \\
\hline
\end{tabular}

Values are means \pm SEM; $n$ is number of obserıations. Abbreviations: MIABP. mean arterial blood pressure; CO, cardiac output: Hb, hemoglobin: WBC, white blood cells. ${ }^{*},<0.05$ represents the probability salues at different time periods compared to those at the baseline (control) calculated by the 2-uay analy sis of variance (Frledman test) followed by Wilcoxon-Wilios" test. 
was $28 \pm 2 \mathrm{mmHg}$ and animals died $30 \mathrm{~min}$ after starting LPS infusion. In survitors there was a marked transient decrease in cardiac output from 25-30 min after starting LPS infusion. Subsequently, cardiac output returned to about baseline levels in spite of the continuous LPS infusion. From $120 \mathrm{~min}$ ( $1 \mathrm{~h}$ after stopping LPS administration) cardiac output again tended to decline, whereas the concentration of LPS in the circulation returned to the baseline levels. In non-survisors, cardiac output decreased quickly to one-third of baseline values within 25 min after the start of LPS infusion.

In non-survivors basal core temperature was higher by $1{ }^{\circ} \mathrm{C}$ than in survivors (Table I, Group II. $p<0.05, \mathrm{n}=17$ ). Temperature was elevated in both groups following LPS infusion.

Laboratory measurements (Table I, Group (I). LPS infusion induced a rapid increase in hemoglobin values, ev ident from $30 \mathrm{~min}$ after commencement of LPS infusion. This hemoconcentration was apparent toward the end of the observation period and did not improve after the LPS infusion was stopped. The LPS infusion was followed by a similar decrease in II'BC and platelet counts at $30 \mathrm{~min}$ of LPS infusion in both survivors and non-survivors. After the LPS infusion was stopped. WBC and platelet counts in the survivors remained significantly lower than baseline. In non-survirors a clear hyperglycemia dereloped, while survivors showed severe hypoglycemia.

\subsection{LPS determinations (Fig. I)}

The basal concentration of LPS was $520 \pm 47 \mathrm{ng}$ $\mathrm{I}^{-1}(n=6)$ in aortic plasma prior to the start of LPS infusion. There were no differences in plasma LPS levels between survivors and non-survivors

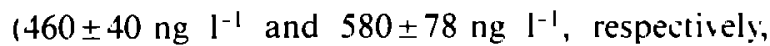
$n=3$ each). A peak in the LPS levels was reached at $30 \mathrm{~min}$ after the start of LPS infusion and remained constant till the end of the intusion period. The differences between peak concentrations observed in survivors and non-survivors were not statistically significant $\left(920 \pm 190 \mathrm{ng} \mathrm{l}^{-1}\right.$ and $1026 \pm 203 \mathrm{ng} \mathrm{l}^{-1}$, $\mathrm{n}=3$ each). The plasma LPS levels rapidly declined after the stoppage of LPS infusion and returned to the baseline in $60 \mathrm{~min}\left(560 \pm 162 \mathrm{ng} \mathrm{l}^{-1}, \mathrm{n}=3\right)$.

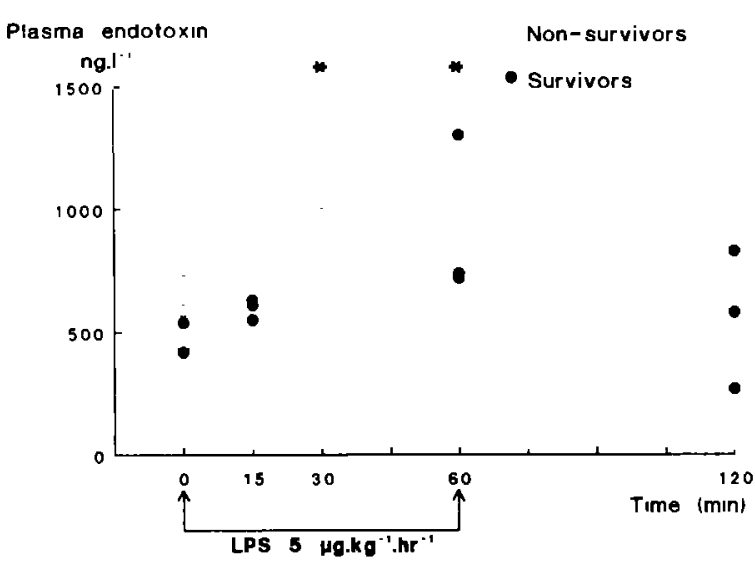

Fig. 1. Aortic plasma endotoxn concentratıons (ng $\left.\right|^{-1}$ / atter en dotoxin (LPS) infusion into the superior mesenteric artery in anesthetized pugs. Endocoun infusion was $5 \mu \mathrm{g} \mathrm{kg}^{-1}$ from (0-60 min. Values are means \pm SEM. Closed crriles indicate those anmals that sursived the observation period of $3 \mathrm{~h}$ after starting LPS infusion tsurvitors, $n=3$ ). Open circles indicate those animals that died in $30 \mathrm{~min}$ after starting LPS infusion inon survivors. $n=31$. ". represents the probabilus values at dillerent ume periods compared to those at the baseline calculated by the - - wav analysis of variance (Friedman test) followed by Milowann"'ilicos" lest.

\subsection{T.NF measurements (Fig. 2)}

Aortic blood samples processed as described contained a substance that was cytostatic for L929 mu

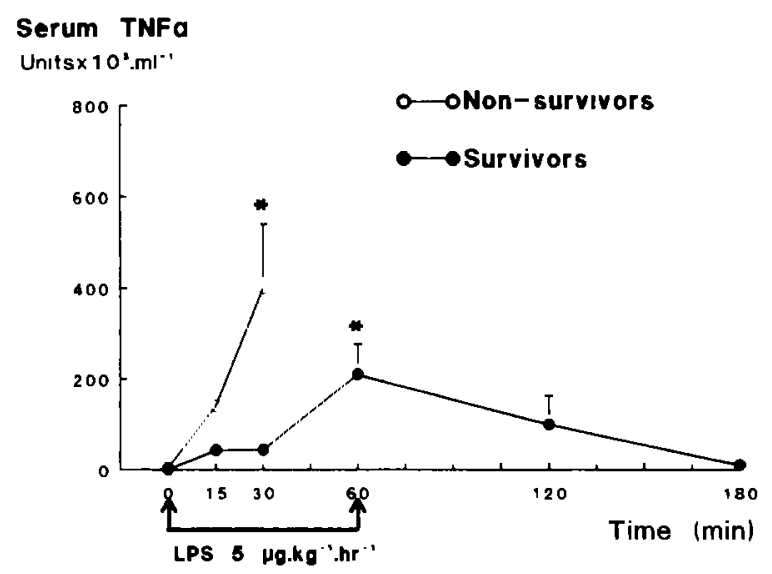

Fig. 2. Time course of the TNFa response to LPS in rusion Or. dinate: TNFa levels in units $\times 10^{3} \mathrm{ml}^{-1}$ as determined by L929 bioassay in aortic serum. TNF $a$ salues in sham-operated group $(\mathrm{n}=3)$ remained under the detection limit $(400)\left(\mathrm{i} \mathrm{ml} \mathrm{ml}^{-1}\right)$. Closed circles indicate the sursitors $(n=4)$, open circles indicate the nonsurvisors ( $\mathrm{n}=5$ ). Other details as in Fig. I. 
rine fibroblast line. In the survivors, TNF was either undetectable or just detectable in the serum until $30 \mathrm{~min}$ of LPS infusion; at 60 min TNF level was clearly increased, but thereafter it declined again. In contrast, a marked increase was detected in TNF release in non-surviıors at the time of death.

\section{Discussion}

Continuous infusion of $5 \mu \mathrm{g} \mathrm{kg}^{-1}$ LPS caused death in 8 out of 17 pigs treated. Some possibilities might be put forward for explaining this split in the pig population, such as genetic control on the amount of TNF released following continuous LPS infusion and or release of other mediators which might dow'n-regulate the release of TNF. In this context, it is claimed that the release of $\mathrm{PGE}_{2}$ might inhibit the release of TNF (quoted in review; ref. 15). In view of the fact that no difference was found in the plasma concentration of LPS between survitors and non-survivors, it seems unlikely that the difference in susceptibility to death is due to a difference in the clearance of LPS.

The death caused by LPS infusion seems to be closely related to the amount of TNF release induced by LPS. This finding is based on determinations of cytostasis against the target cell-line L929 (selectively sensitive to TNF; refs. 13 and 14) by serum obtained from LPS-treated pigs. It should be noted that the test sera used also contain a certain quantity of LPS and, possibly, interleukin I (IL-1) released either by a direct effect of LPS [16] and ior as a sequel to TNF release [16]. It has been mentioned that some other factors present in the serum (besides TNF), might affect activity against L929 cells [14]. Howeter, circumstantial evidence is strongly in favor of the assumption that the cytostatic effect of serum from LPS-treated pigs is due to the TNF. This assumption is supported by our observations that LPS itself is not cytostatic against L929 cells (data not shown) and by findings of others that L 929 cells are nor susceptible to IL-1 [17]. Accordingly; it seems likely that death is caused in a certain percentage of LPSinfused pigs by a marked increase in TNF release as the main mediator for lethality:

The findings of different susceptibility to the lethal effect of LPS in a specified population of pigs provides an experimental model for determining the relation between lethal effect and endotoxic shock.
In this respect, it is of interest that pigs surviving LPS infusion remained in a state of shock up to the end of the 120-min observation period, i.e., long after termination of LPS infusion and after the blood levels of LPS and of released TNF returned to basal values. The shock state was ascertained by systemic hypotension, low cardiac output, hemoconcentration, leukocytopenia and hy'poglycemia. The results, indicating a shock state in surviving pigs long after LPS and TNF levels returned to baseline, suggest that other mediators besides or instead of TNF are responsible for the endotoxic shock observed. The release of these mediators (PAF, eicosanoids) might be evoked by LPS itself [16] and'or TNF.

In conclusion, we show here a clear distinction between LPS-induced death and LPS-induced shock. This finding implies that different mediators may be involved in these two events.

\section{Acknowledgements}

We wish to thank Dr. A. Sturk and Dr. C. H. Wortel (both of the Department Hematology, Academisch Medisch Centrum, Amsterdam, The Netherlands) for the endotoxin assays and helpful discussions, respectively. The authors appreciate the excellent laboratory assistance of Mr. W'. P. van Schalkwijk (Laboratory for Experimental Surgery, Erasmus University Rotterdam). This work is supported by the Dutch Cancer Society, the Emil Starkenstein Foundation and the University Foundation Rotterdam ("Stichting Universiteitsfonds Rotterdam"). T.M. is the recipient of a Fellowship Award (1989-90) from the Surgical Infection Society, Europe (sponsored by ICI Pharmaceuticals).

\section{References}

[1] Beutler. B. and Ceramı, A. (1988) Annu. Rer, Biochem. 5?. 505

[2] Mihie, H. R.. Manoque. K. R.. Spriggs, D. R.. Rer haug, A.. O'Dwyer. S., Dinarello. C. A.. Cerami, A., Molfi. S. M. and W'ilmore, D. W' (1988) N. Engl. J. Ned. 318, 1481.

[3] Feuerstein. G., Hallenbeck. J. M1., Vanatta, B., Rabinovici. R., Perera. P. Y. and Vogel. S. N. (1990) Cire. Shoik 30. 265

[4] Waage, A.. Halstensen, A. and Esperih, T. $\left(198^{\prime}\right.$ ) Lancet i. 355.

[5] Beutler, B., Mlısark, I. W' and Cerami, A. (1985) Science 229. 869

[6] Trace, K. J., Fong. Y.. Hesse, D. G., Manoque, K. R., Lee. A. T., Kuo, G. C. Lowry, S. F. and Cerami. A. (1987) Nacure 
330, 662.

[7] Mathison, J. C., Wolfson. E. and Uleutch, R. J. (1988) J. Clın. Invest. 81. 1925.

[8] Trace.. K. J., Beutler. B., Loury, S. F.. Merrỵucather. J.. Wolpe, S., Milsark, I. W'. Hariri. R. J., Fahey, T. J.. Zentella. A., Albert, J. D. Shires. G. T. and Cerami, A. (1986) Science 234. 470 .

[9] Ohusara. S., Geliand. J. A.. Ihejıma, T., Conolly. R. I. and Dinarello. C. A. (1988). J. Clin. Invest. 81, 1162.

[10] Redl, H., Sihlag, G., Lamche, H., with technical assistance of Vogl. C., Paul, E., Schsesser, A.. W'ilfing, C.. Thurner, N1. and the Biomedical Engineering Group (1990) Circ. Shoih 31. 183 .

[1I] Mózes, T., Braquet, P and Filep. J. (1989) Am. I. Phısılol.
257 (Reg. Integr. Comp. Phısiol. 261, R872.

[I2] Sturk, A.. Janssen. M. E.. Muylaerth, F. R., Joop. K., Thomas, L. L. M. and Ten Cate. J. W. (1987) Prog Clin. Biol. Res. 231, 3i1.

[13] Hay. H. and Cohen, J. (1989) J. Clın. Lab. Immunul 2R. 151

[1+] Meager, A.. Leung. H. and Walle\}. J. (1989) J. Immunol. Methods 116. 1.

[I5] Bonta. I. L. and Ben-Eiraim. S. $1199(1)$ Immunol Lell. 25. 295.

[16] Morrison, D. C. and Ŗan. I. L. 11987) Annu. Rer. Mled 3s. $41^{7}$.

[I7] lchınose. Y.. Tsao, 1. I. and Fidler. I. I (1988) Cancer In. munol. Immunother. 27. ?. 